\title{
Bilateral Differences in Peak Force, Power, and Maximum Plié Depth During Multiple Grande Jetés
}

\author{
Matthew Wyon, PhD, Julie Harris, MSc, Derrick Brown, MSc, and Frances Clarke, MSc
}

\begin{abstract}
A lateral bias has been previously reported in dance training. The aim of this study was to investigate whether there are any bilateral differences in peak forces, power, and maximum knee flexion during a sequence of three grand jetés and how they relate to leg dominance. A randomised observational design was selected for the study. Volunteers consisted of 20 female dancers in the last year of pre-professional training. All volunteers completed three different tests to determine leg dominance prior to completing a three grande jeté sequence. The lead leg for the jump sequence was randomised. Peak take-off power, relative landing force (BW), and maximum knee flexion angles were measured using a Myotest accelerometer and integrated goniometer. Results indicated that $90 \%$ of dancers reported right leg dominance. A significant difference was noted in peak take-off power among the jumps $(p<0.01)$; post hoc test indicated jump 3 was significantly greater than jump 1. Mean maximum take-off knee angles increased over the three-jump sequence with the left leg having a significantly deeper plié than the right $(p<0.01)$. Landing data showed an increase in peak force and a decrease in maximum knee angles across the jump sequence. The present data indicate different bilateral strategies during take-off and landing during grand jetés in female dancers resulting in increased forces during the jumps on the non-dominant side. These differences need to be addressed by incorporating appropriate modifications in training methodology that eliminates the observed bilateral differences. Med Probl Perform Art 2013; 28(1):28-32.
\end{abstract}

$\mathrm{D}$ ance is a complex body action based on a combination of different components, ${ }^{1}$ each of which needs to be adequately addressed and developed in a dancer's training programme. ${ }^{2,3}$ All dance movements are reliant on the forces acting on the body from gravity and from interactions between the body and the floor. When a dancer does not utilise a demi-plie during a landing, a relatively large vertical ground reaction force (VGRF) is sustained over a short time interval. ${ }^{4,5}$ Landing efficiently, via a controlled deceleration of body segments through a plié, can lower ground reaction forces thereby reducing occurrence of injury. ${ }^{5-7}$ Previous research has shown that jump height and VGRF on landing have strong positive correlations with plié depth. ${ }^{8-10}$ However, these data were obtained from single jumps.

Dr. Wyon, Ms. Harris, Mr. Brown, and Ms. Clarke are from the Research Centre for Sport Exercise and Performance, University of Wolverhampton, Walsall, UK; Dr. Wyon is also affiliated with the National Institute of Dance Medicine and Science, UK.

Address correspondence to: Dr. Matthew Wyon, Research Centre for Sport Exercise and Performance, University of Wolverhampton, Gorway Rd., Walsall, West Midlands WS1 3BD, UK. Tel 44 01902-323144, fax 44 01902322894.M.Wyon@wlv.ac.uk.

(C) 2013 Science $\mathcal{E}$ Medicine. www.sciandmed.com/mppa.
Due to choreographic needs, the dancer must also be proficient in performing skills on both sides of the body. ${ }^{11}$ However, Kimmerle ${ }^{11}$ and Hays ${ }^{12}$ have commented that dance training has led to bilateral differences within the body. Widely accepted teaching practices across the different dance forms appear to favour exercises and routines starting on the right side. Consequently, dancers normally have extensive learning experience on one side (typically the right) and most students feel more comfortable favouring that side. In sport, bilateral bias is not perceived as a problem, as one-sided expertise is often considered the norm, i.e. athletes often pitch, serve, kick a field goal from a preferred side. ${ }^{11}$ Interestingly, there has been little reporting of lower limb bilateral differences in power production, ${ }^{13}$ balance, or muscular patterning, ${ }^{14,15}$ though bilateral differences were noted in VGRF ${ }^{16}$ and for strength in the upper limbs, ${ }^{17}$ but not for the lower ones. ${ }^{18}$

As noted above, published data on jump characteristics in dancers have been obtained from single jumps. ${ }^{8-10}$ However, given that stage dance performances very rarely contain single jumps, the aim of the present study was to investigate whether there are bilateral differences during a three-jump sequence. The grand jeté was utilized, which is a split jump often used in a sequence of three jumps and where dancers are expected to generate both height and distance (Fig. 1).

\section{METHODS}

A randomised observational experimental design was adopted to assess bilateral differences in peak take-off and landing forces and in maximum knee flexion during a sequence of three grand jetés and to evaluate how they relate to leg preference. Each dancer was required to carry out two three-split jump sequences. The lead leg for the jump sequence was randomised. The dependent variables were plié depth (degrees), centre of mass take-off power (Watts), and centre of mass landing force (BW).

\section{Subjects}

A total of 20 female dancers volunteered for the study (Table 1). All participants were in the final year of a pre-professional contemporary dance programme at a dance conservatoire. The participants were injury free, and each completed and signed an informed consent form and pre-test health questionnaire. The protocol was approved by the authors' university ethics committee prior to commencement of data collection. 


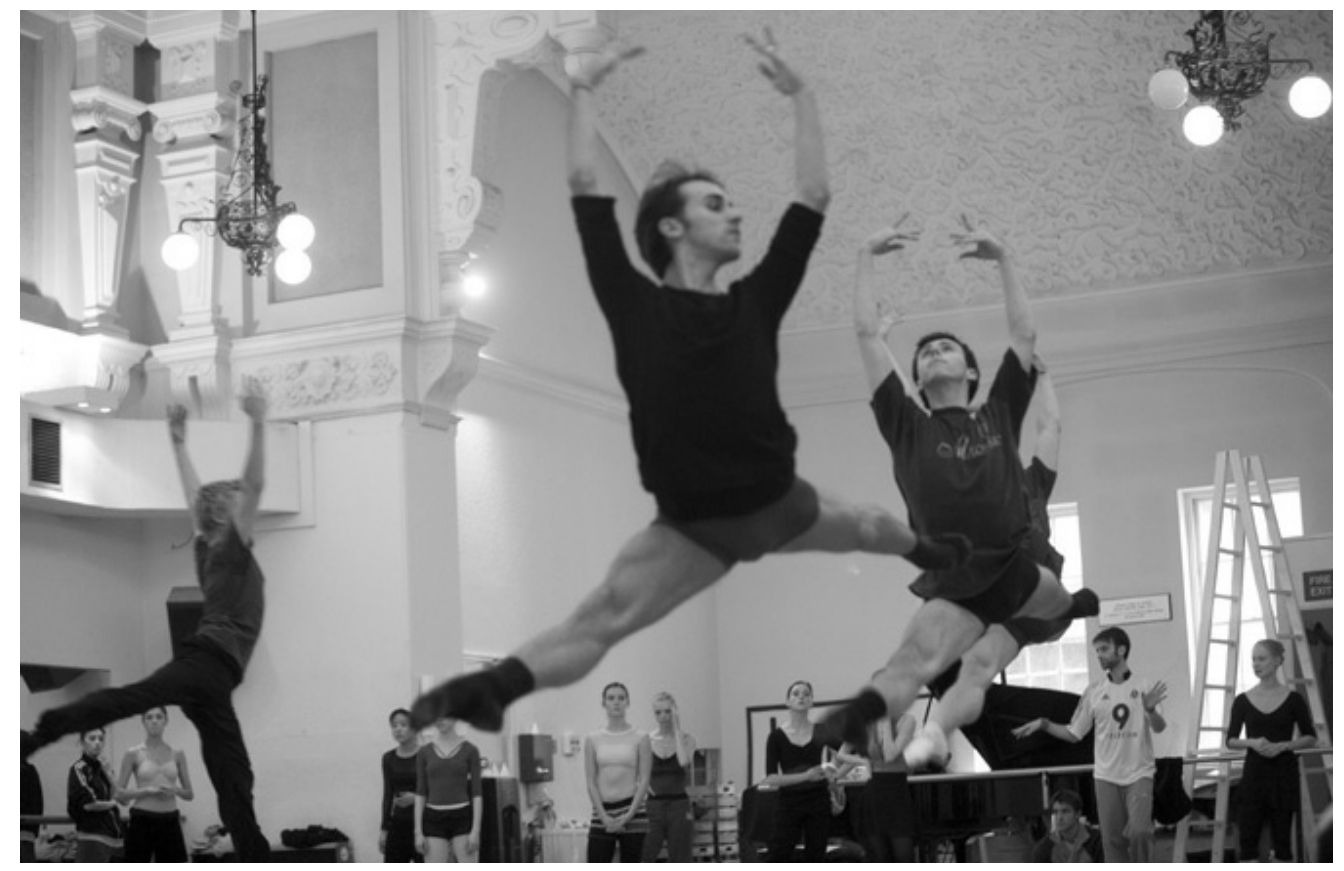

FIGURE 1. Grand jetés. (Asya Verzhbinsky, photographer; courtesy of the English National Ballet Company).

\section{Procedures}

\section{Pilot Study}

The reliability of the Myotest accelerometer and goniometer (Acceltec, Switzerland) were assessed prior to data collection. Eight participants carried out two separate maximal countermovement jumps with the accelerometer attached to the lower back and the goniometer centred on the lateral aspect of the right knee. Significant Pearson product correlation scores were noted for take-off power $(r=0.92, p<0.05)$, landing force $(r=0.91, p<0.05)$, and maximum plié depth (knee flexion) $(r=0.89, p<0.05)$.

\section{Protocol}

To determine leg preference, participants were instructed to carry out three tests, two physical and one question. ${ }^{13,19,20}$ The two physical tests consisted of a step-up onto a bench and stomping on a specific spot marked on the floor. The tester phrased the instructions as "step/stomp with any leg." The leg the participant stepped with and stomped was labelled the participant's preferred leg. The participant was further asked which leg is their preferred leg, the leg they felt most comfortable to use. The leg that scored two out of the three tasks was designated as the preferred leg.

All participants had a Myotest accelerometer attached to their lower back, centred on L4-5, and its integrated

TABLE 1. Participant Descriptive Data

\begin{tabular}{ccccc}
\hline & $\begin{array}{c}\text { Age } \\
(\mathrm{yrs})\end{array}$ & $\begin{array}{c}\text { Weight } \\
(\mathrm{kg})\end{array}$ & $\begin{array}{c}\text { Height } \\
(\mathrm{cm})\end{array}$ & $\begin{array}{c}\text { Leg } \\
\text { Dominance }\end{array}$ \\
\hline Female $(n=20)$ & $20 \pm 1.74$ & $54 \pm 3.2$ & $165 \pm 2.5$ & $90 \%$ right leg \\
\hline
\end{tabular}

goniometer to the lateral aspect of their lead/landing knee (Fig. 2). After a 10-minute standardised warm-up, all participants were asked to carry out two trials of three grande jetés, with three runs in between each jump. The grande jeté is a split leap jump where the dancer leads with one leg, e.g., with the right leg leading, the left leg generates the power during the take-off and the right leg is used during the one-legged landing. Participants were asked to jump as high as possible each time; use of arms was allowed but standardized to third position below shoulder height. All tests were carried out on the same day within a 1-hour slot, prior to the commencement of scheduled dance activity.

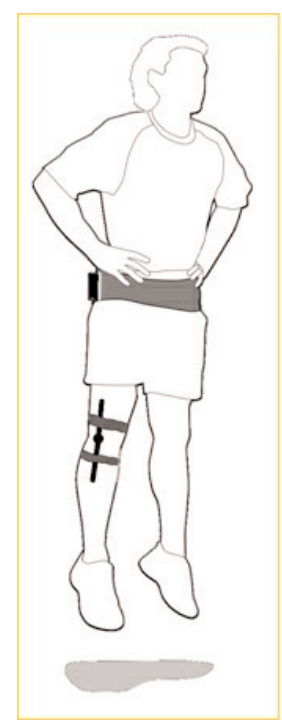

FIGURE 2. Placement of Myotest accelerometer and goniometer. 
TABLE 2. Descriptive Data for Landing Force, Take-Off Power and Knee Flexion

\begin{tabular}{|c|c|c|c|c|}
\hline & \multirow[b]{2}{*}{ Leading Leg } & \multicolumn{3}{|c|}{ Jump } \\
\hline & & 1 & 2 & 3 \\
\hline Take-off power (W) & Right & $3663 \pm 1229^{*}$ & $3882 \pm 1336$ & $5364 \pm 1746^{*}$ \\
\hline \multirow[t]{2}{*}{ Take-off knee angle $\left({ }^{\circ}\right)$} & Right & $115 \pm 26.68$ & $120 \pm 26.72$ & $119 \pm 26.01$ \\
\hline & Left & $99 \pm 28.08$ & $102 \pm 29.58$ & $102 \pm 29.57$ \\
\hline \multirow[t]{2}{*}{ Landing knee angle $\left(^{\circ}\right)$} & Right & $149 \pm 16.84$ & $144 \pm 16.91$ & $136 \pm 29.23$ \\
\hline & Left & $139 \pm 34.39$ & $135 \pm 34.27$ & $135 \pm 35.01$ \\
\hline
\end{tabular}

*Significant $p<0.05$.

Data were collected at $1.5 \mathrm{KHz}$ and down sampled to 500 $\mathrm{Hz}$ by averaging every three data points. Initial data analyses involved calculation of plié depth during the take-off and landing phases of the jumps (maximum angle of knee flexion), power (Watts), and peak force (Newtons), as measured through the centre of mass (CoM) accelerations for all completed jumps. The peak force was further manipulated by converting the Newton data to body weight equivalents (BW) using the equation Newtons/body weight.

\section{Statistical Analyses}

The three-jump-sequence data were analysed using univariate ANOVA with leg and jump number as fixed factors; post hoc Scheffe tests were carried out for jump differences and observed power calculated for all variables. Pearson product correlation analysis compared peak landing force and take-off power with the respective maximum knee flexion (plie depth) for left and right legs. The alpha level was set at $95 \%(p<0.05)$ for all tests.

\section{RESULTS}

A significant difference was noted in take-off $\mathrm{CoM}$ power between the three jumps for combined data $\left(F_{2,114}=6.24\right.$; $p<0.01$, observed power 0.89); post hoc test indicated jump 3 was significantly greater than jump 1; though no significant bilateral difference was noted (Table 2). Mean data for takeoff knee angles (Table 2) indicated a non-significant increase over the three-jump sequence, though a significant difference was noted between the legs $\left(\mathrm{F}_{1,108}=10.92 ; \mathrm{p}<0.01\right.$; observed power 0.91 ). Centre of gravity landing force data showed a non-significant increase in force and a non-significant decrease in knee angles across the jump sequence (Table 2); again, no significant bilateral differences were observed.

Correlation analysis of the left and right legs combined revealed a significant relationship between knee flexion angles during take-off and landing $(r=0.68, p<0.01)$ and a small, but significant, negative relationship between knee flexion and landing force $(r=-0.29, p<0.01)$. Analysis of indi-

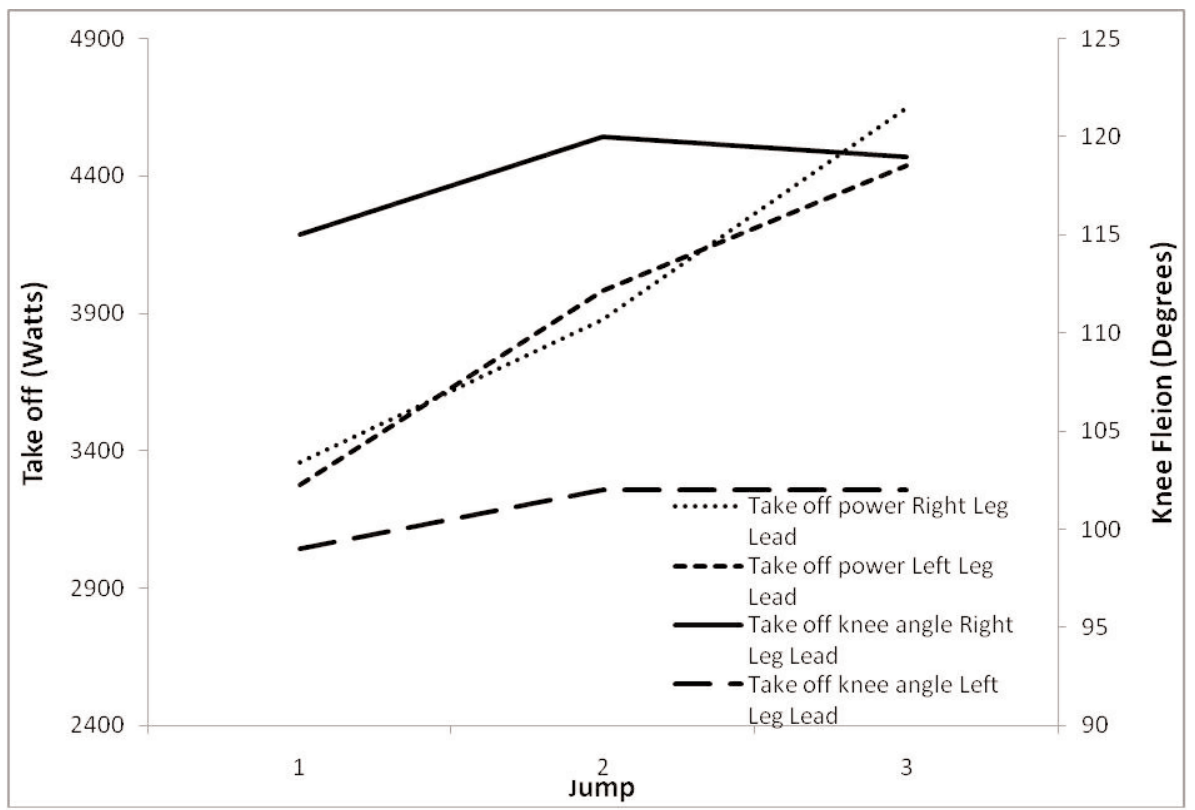

FIGURE 3. Bilateral mean data for take-off indices for the three jumps. 


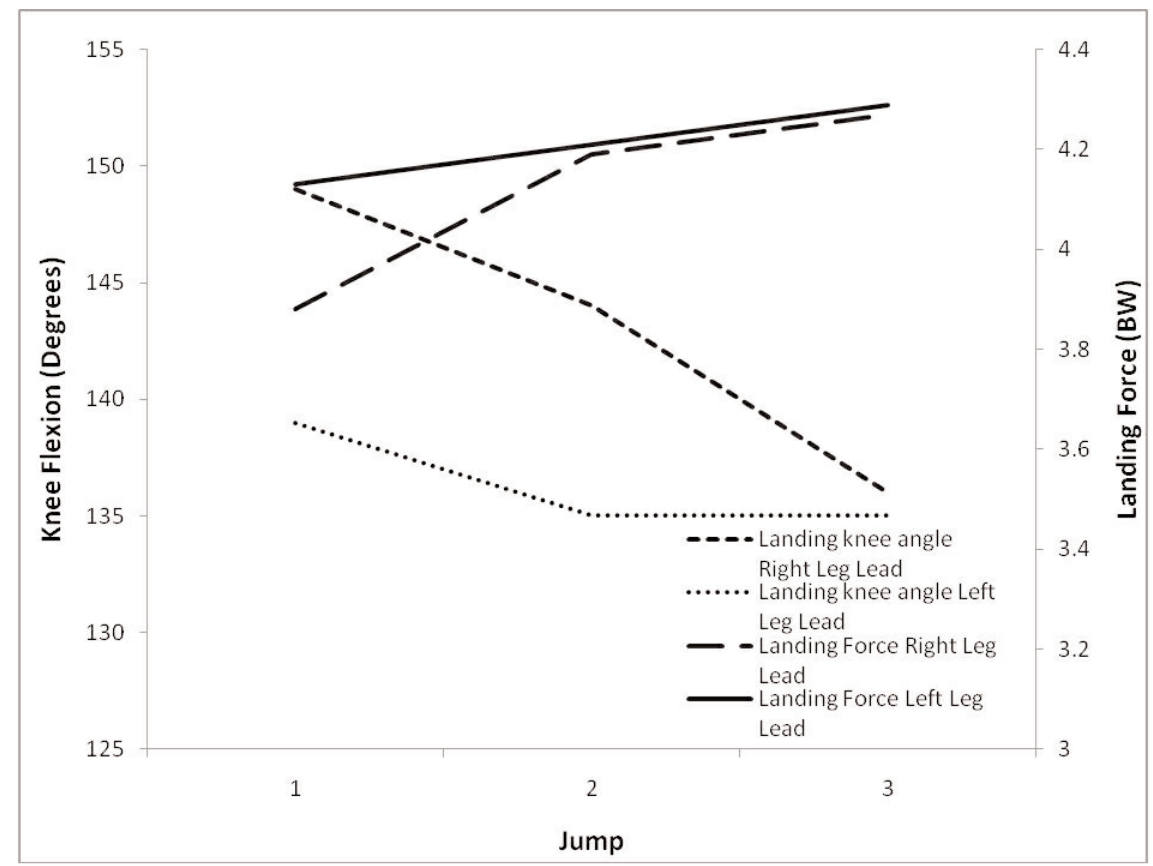

FIGURE 4. Bilateral mean data for landing indices for the three jumps.

vidual legs highlighted differences in laterality; preferred leg leading data demonstrated a positive significant relationship between take-off power and knee flexion $(r=0.26, p<0.05$, Fig. $3)$ and a significant negative correlation between knee flexion and landing force $(r=-0.60, p<0.01$, Fig. 4). Non-dominant leg leading data indicated a significant negative correlation between take-off power and knee flexion $(r=-0.29, p<0.05)$ and a nonsignificant correlation between maximum knee flexion angle and landing peak force.

\section{DISCUSSION}

The aim of the present study was to investigate whether there are any bilateral differences in peak take off power and landing force and maximum knee flexion during grand jetés and how they relate to leg dominance. Despite the common belief in dance ${ }^{11}$ that one side of the body is stronger than the other, the current lack of bilateral differences reinforces published data which found a lack of bilateral variation in the lower limbs. ${ }^{13-15,21,22}$ The limb preference in the general population has been associated with skill rather than power and stability movements. ${ }^{23}$ In ballet, high skill movements, such as tendus and frappés, are mainly choreographed for the right leg, whilst the left leg provides the stability and power for movements such as pirouetting and jumping.

Analysis of the three-jump sequence indicated a significant increase in take-off power over the three-jump sequence with a similar though not significant increase in take-off knee angle (plié depth) which corresponds to the observed correlation between plié depth and take-off power. Plié depth during take-off peaked during jump 2 even though there is a subsequent increase in take-off power for jump 3 . This suggests the increase in power output stems from the utilisation of kinetic energy derived from the previous jumps. ${ }^{24}$ The significantly greater knee angles seen with the right leg leading (left leg take off) did not produce significantly greater take-off power than the other leg. The lack of plie depth could be due to either the right leg being stronger and, therefore, less of a plié was required to achieve the desired power output, or, as dancers are not used to carrying out one leg pliés on this leg, there is a loss in leg stability during deeper plies. ${ }^{25-27}$ The poor correlation between knee angle and take-off power could be due to the fact that only the knee joint was assessed for the purpose of this study; within the jete's kinetic chain, the ankle and hip joints will also contribute to the power output. ${ }^{27,28}$

The significantly greater knee flexion, or plié depth, during landing for the right leg leading during jumps 1 and 2 is possibly a training effect as previously suggested. ${ }^{11}$ Dancers are trained from an early age to plié on landing from a jump and the teaching styles that favour the right leg training could cause this difference in knee flexion. This is clearly seen during the first jump; when the right leg is employed on landing, a much greater knee flexion occurs causing lower peak forces compared to the equivalent data during the same left leg landing. Published data revealed that thigh girth circumferences were greater in the right leg than the left, and this was probably due to the hypertrophical effects of the eccentric muscle action during jump landing. ${ }^{29}$

It is noteworthy that knee flexion angles on landing for both legs decreased over the three-jump sequence and caused increased peak force. Potential reasons for this are that the last jump has the greatest take-off power and, therefore, was probably the highest, resulting in greater landing force, 
and/or that the dancers were focusing on generating take-off power rather than shock-absorption during the landing, which anecdotal evidence seems to support. Dance teachers need to teach technical skills on both legs equally to help reduce the observed imbalance. The previously reported high leg injury rates noted within the dance population ${ }^{30}$ could be a cause of faulty technique within the landing phase of jumping, and the present study highlights the lack of skill within the nondominant leg during this phase. There is also a need for supplemental training, particularly containing one-leg eccentric muscular actions, that focuses on the landing and take-off aspects of jumping as well as addressing the potential nondominant leg's functional instability thereby allowing a deeper plié on landing.

\section{CONCLUSION}

Though little bilateral difference was noted within the present study, right leg dominance theory seems to be reflected by the present data, which indicate potential different bilateral strategies during take-off and landing during grand jetés in female dancers. Further research is required to assess whether this effect is exaggerated when the dancer is fatigued, and whether an intervention period that emphasises learning with the nondominant leg rectifies differences between legs.

\section{REFERENCES}

1. Koutedakis Y. Jamurtas A. The dancer as a performing athlete: Physiological considerations. Sports Med 2004;34(10): 651-661.

2. Ashely L. The essential guide to dance, 2 nd ed. London: Hodder \& Stoughton; 1996.

3. Koutedakis Y, Sharp NCC. The Fit and Healthy Dancer. Chichester, UK: John Wiley and Sons; 1999.

4. Laws K. Physics and the Art of Dance: Understanding Movement. New York: Oxford University Press; 2002.

5. Lees A. Methods of impact absorption when landing from a jump. Engl Med 1981;10(4): 207-11.

6. Mizrahi J, Susak Z, In-vivo elastic and damping responses of the human lag to impact forces. J Biomech Eng 1982; 104: 63-6.

7. Paskevska, A., Both Sides of the Mirror: The Science and The Art of Ballet, 2nd ed. Pennington: Princeton Book Co; 1992.

8. Salci Y, Kentel B, Heycan C, et al. Comparison of landing manoeuvers between male and female college volleyball players. Clin Biomech 2004;19(6): 622-8.

9. Macintyre J, Joy E. Foot and ankle injuries in dance. Clin Sports Med 2000;19(2): 351-468.

10. Suter W, One-year changes in hind limb kinematics, ground reaction forces and knee stability in an experimental model of osteoarthritis. J Biomech 1998;31(6): 511-7.

11. Kimmerle M. Lateral bias in dance training. J Phys Educ Rec Dance 2001;72: 34-37.
12. Hays J. Modern Dance: A Biomechanical Approach to Teaching. St Louis: Mosby; 1981.

13. Challis J. An investigation of the influence of bilateral deficit on human jumping. J Hum Mov Stud 1998;17(3): 307-25.

14. Harrison E, Duenkel N, Dunlop R, Russell G. Evaluation of single-leg standing following anterior cruciate ligament surgery and rehabilitation. Phys Ther 1994;74(3): 245-52.

15. Lucca J. Kline K. Effects of upper and lower limb preference on torque production in the knee flexors and extensors. J Orthop Sports Phys Ther 1989;11(5): 202-7.

16. Hawkey A, Lahart I. Effects of bracing dominant and non-dominat ankles on lateral peak impact forces during cutting manoeuvers in male basket ball players. J Sport Sci 2008;25(s2): s88.

17. Hartsell H, Hubbard M, Van Os P, Isokinetic strength evaluation of wrist pronators and supinators: Implications for clinicians. Physiother Can 1995;47(4): 252-7.

18. Koutedakis Y, Myszkewycz L, Soulas D, et al. The effects of rest and subsequent training on selected physiological parameters in professional female classical dancers. Int J Sports Med 1999;20(6): 379-383.

19. Cloak R, Galloway S, Wyon M. The effect of ankle bracing on peak mediolateral ground reaction force during cutting manoeuvres in collegiate male basketball players. J Strength Cond Res 2010;24(9): 2429-2434.

20. Reid DC, Burnham RS, Saboe LA, Kushner SF. Lower extremity flexibility patterns in classical ballet dancers and their correlation to lateral hip and knee injury. Life Sci 1991: 189-199.

21. Ersoz M, Atalay N, Kumbara F, Akyuz M. Investigation of effect of age, gender and limb dominance on ankle evertor/invertor peak torque rations of healthy volunteers. J Phys Ther Sci 2009;21: 263-267.

22. Hoffman M, Schrader J, Applegate T, Koceja D. Unilateral postural control of the functionally dominant and nondominant extremities of healthy subjects. J Athl Train 1998;33(4): 319-322.

23. Sadeghi H, Allard P, Prince F, Labelle H, Symmetry and limb dominance in able-bodied gait: a review. Gait Posture 2000;12(1): 34-45.

24. Gehri D, Ricard M, Kleiner D, Kirkendall D. A comparison of plyometric training techniques for improving vertical jump ability and energy production. J Strength Cond Res 1998;12(2): 85-89.

25. Hamilton R, Shultz S, Schmitz R, Perrin D. Triple-hop distance as a valid predictor of lower limb strength and power. J Athl Train 2008;43(2): 144-151.

26. Myer, G, Ford K, Brent J, Hewett J. The effects of plyometric vs. dynamic stabilization and balance training on power, balance, and landing force in female athletes. J Strength Cond Res 2006;20(2): 345-353.

27. Valdez D. Bilateral asymmetries in flexibility, stability, power, strength, and muscle endurance associated with preferred and nonpreferred leg. In: Applied Physiology and Kinesiology. Gainsville: Univ of Florida; 2003: p120.

28. Hubley C, Wells R. A work-energy approach to determine individual joint contributions to vertical jump performance. Eur J Appl Physiol Occup Physiol 2004;50(2): 247-254.

29. Wyon M, Allen N, Angioi M, et al. Anthropometric factors affecting vertical jump height in ballet dancers. J Dance Med Sci 2006;10(3/4): 106-110.

30. Laws H. Fit to Dance 2-Report of the Second National Inquiry Into Dancers' Health and Injury in the UK. London: Newgate Press; 2005. 